\title{
Resident and visitor perceptions of island tourism: green sea turtle ecotourism in Penghu Archipelago,Taiwan
}

\author{
Yu-Long Chao \\ Center for General Education, National Formosa University, Taiwan \\ chaoyulong@gmail.com (corresponding author)
}

\author{
Shang-Yu Chao \\ Chi-Mei Elementary School, Penghu County, Taiwan \\ fish08307@gmail.com
}

\begin{abstract}
This study compares residents and visitors on the island of Wang-An in Penghu archipelago (Taiwan) in terms of four variables (ecotourism perception, environmental attitude, ecotourism behavior, local environmental knowledge). Results show that island visitors are positioned closer to the deep end of a shallow-deep spectrum on a few ecotourism characteristics such as stronger environmental commitment, smaller groups, and more personal experience. With a fuzzy cluster analysis reducing the four variables to two dimensions (ecotourism literacy, environmental familiarity and concern), the two clusters of island residents and visitors are found to overlap greatly with a noticeable divergence in the dimension of environmental familiarity and concern as a result of residents' better local environmental knowledge. Residents express greater approval of economic development on some items of the environmental attitude subscale. It is recommended that visitors have longer tours that increase interaction with residents to learn more about the local environment while serving as educators of ecotourism.
\end{abstract}

Keywords: ecotourism, environmental attitude, fuzzy cluster analysis, island tourism, local environmental knowledge, Penghu archipelago, Taiwan

https://doi.org/10.24043/isj.27

(C) 2017 — Institute of Island Studies, University of Prince Edward Island, Canada.

\section{Introduction}

Penghu, also known as the Pescadores, is an archipelago county of Taiwan in the Taiwan Strait. Among Penghu's 18 islands, Wang-An is known for its green sea turtles. This small island has a human population of around 1,000 and an area of $7.2 \mathrm{~km}^{2}$ (Figure 1). Wang-An is the only island on which Taiwan's Council of Agriculture has established a habitat protection area for egg-laying green sea turtles (since 1995), and the island is recommended by the Penghu National Scenic Area Administration for its sea turtle ecotourism. Ox carts, fishing nets, coral stone walls, columnar basalt cliffs, and temples are characteristic of the island's distinctive landscape, shaped by traditional culture. At the culmination of the Lunar New Year Lantern Festival, islanders traditionally visit temples to worship the gods, making offerings in the shape of turtles, purportedly symbolizing the sea turtles' annual laying of eggs on the island's beaches between May and October. Sea turtles feature prominently in Wang-An's ecotourism. It is not, however, immediately clear that such tourism activities genuinely represent ecotourism. In terms of the conservation of natural resources, perception of ecotourism by both visitors and island residents determines what these actors foresee as the destination's environmental future.

Penghu as a whole has been affected by the ecotourism trend. Since mainstream economic activities take place on the main island of Taiwan, with the result that Taiwan's outlying islands cannot match the main island's convenient lifestyles or economic development, many residents 
of small islands are eager to be involved in and develop local economic prosperity. Penghu is the largest of Taiwan's outlying archipelagos, with the greatest number of visitors, who are often somewhat 'forced' to plan multiple-day trips to intended sites due to transport limitations.

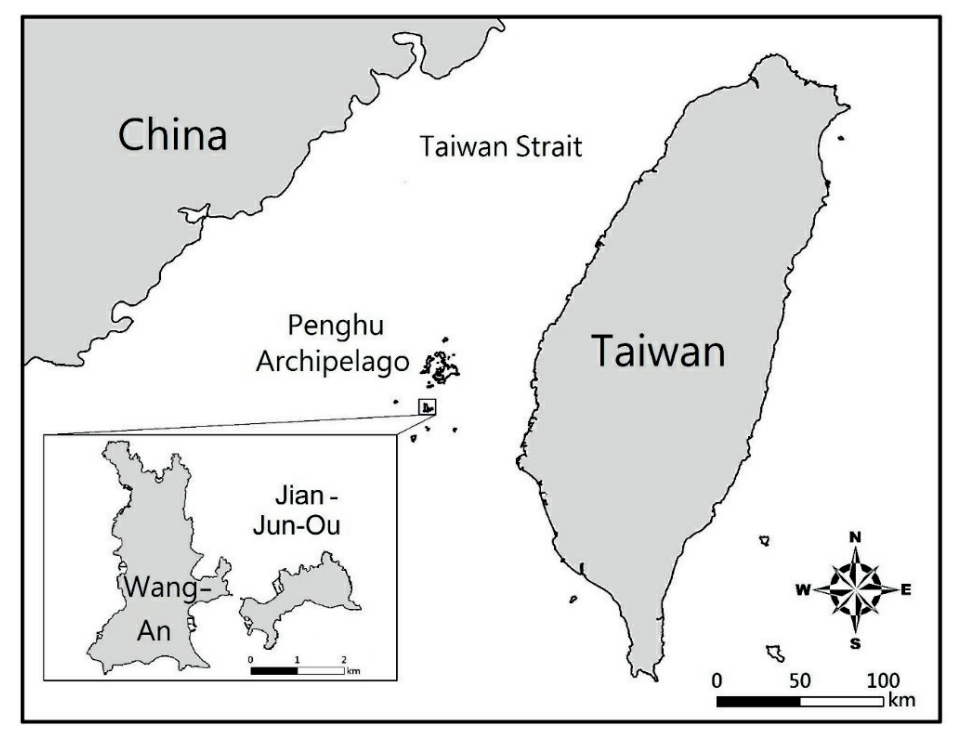

Figure 1: Location of Wang-An island in the Penghu archipelago. (C) Cheng-Dar Yue)

Wang-An in Penghu has thus been chosen as a case study of transformation from a shallow ecotourism to a deep ecotourism that accentuates the profound value of local environmental resources and thereby active commitment to conservation. Moreover, this study asks what happens when visitors come to the island, stay with local residents, and are faced with the same natural landscape: do both visitors and residents share the same imagination of the island's future? The study compares the depths of visitors' and residents' perceptions concerning ecotourism. The differences between these two groups can be illustrated along a set of continua, each with two endpoints of shallow and deep representation for an ecotourism characteristic. Comparisons and analyses between the two groups also cover other aspects, such as local environmental knowledge (LEK), environmental attitude, and ecotourism behaviour. These comparisons and analyses clarify where visitor and resident perceptions of ecotourism diverge or resemble one another and where they are positioned at the shallow or deep ends of the continua. These findings are important for increasing the effectiveness and precision of efforts to move either or both groups toward deep and sustainable ecotourism. An investigation into local environmental knowledge on the part of both residents and visitors generates findings that suggest that activation and enrichment of local environmental knowledge could support advocacy for deeper ecotourism.

\section{Literature review}

Ecotourism ideally represents a more responsible and sustainable way of engaging in tourist activities. There has never been a dichotomous conceptualization of ecotourism or nonecotourism for any given tourist activity, but perspectives on tourism have undergone a continuous process of transformation from conventional forms to the ecotourism ideal. On the continuum of ecotourism paradigms (Miller \& Kaae, 1993), ecotourism is divided into types with varying degrees of tourist responsibility, ranging between passive and active ecotourism. The passive ecotourism to one end of the continuum approves of activities of any kind and intensity that satisfy the needs of the general public. Passive ecotourism is expected to reduce environmental impacts while providing tourists with natural experiences. The active ecotourism to the other end of the continuum emphasizes environmental ethics with an attempt to maintain environmental health. It represents responsible engagement in tourism and, at its extreme, it means that no tourist activity can be permitted to produce negative environmental impacts. A similar treatment of 
differentiating the ideal of ecotourism between two opposites can be found in Weaver and Lawton's (2002) work. They apply two ends of hard (active, deep) and soft (passive, shallow) ecotourism to ten characteristics, as shown in Figure 2. As far as the comparison of ecotourism realization between groups of people is concerned, these characteristics provide a quite comprehensive framework.

\begin{tabular}{lr}
\hline Hard \\
(Active, Deep)
\end{tabular} $\begin{array}{r}\text { Soft } \\
\text { Strong environ. commitment }\end{array}$

Figure 2: Characteristics of deep-shallow ecotourism. (Source: Weaver and Lawton, 2002)

It is also necessary to consider from where the differences in ecotourism depth derive when comparing visitors and island residents. Having lived on an island for generations, local residents should possess deeper knowledge of the local environment than do visitors who stay for just a few days, meaning that local environmental knowledge (LEK) could be the major difference between the two groups. LEK refers to the body of knowledge a certain group of people possess about their local environmental resources (Scholz et al., 2004; Robertson \& McGee, 2003). LEK "can be multifaceted, combining scientific and experiential frames of reference" (Bell et al., 2008, p. 278) and is woven into and inseparable from culture (Kimmerer, 2002). LEK differs from general, scientific environmental knowledge in the sources and acquisition of knowledge and is a result of the interaction between environmental perception and environmental understanding in a given local context. Local people sometimes know the environment better than outside 'experts' because the locals possess a more subtle contextual ecological knowledge (Gawler, 1998). For example, it has been demonstrated that fishermen's knowledge concerning sea turtles has the potential to inform and refine data within conservation science (Küyük et al., 2007; Johannes \& Neis, 2007).

Lye (2007) indicates that LEK is most noticeable in communities that have developed deep-rooted and sophisticated understandings of place. Walter (2009), however, deems that the role of local knowledge, which contains holistic traditional ecological knowledge as the foundation of educating both local people and visitors, is not considered in community-based ecotourism. In response, we propose that island residents should make the most of LEK as an asset for ecotourism development. The question then becomes whether the LEK of islanders involved in ecotourism is positively associated with their ecotourism perceptions and behaviours.

Numerous studies have addressed the segmentation and categorization of tourists by varied environmental attitudes or concerns (e.g. Uysal et al., 1994; Jurowski et al., 1995; Silverberg et al., 1996; Formica \& Uysal, 2001; Zografos \& Allcroft, 2007; Mehmetoglu, 2010; Puhakka, 2011; Kim \& Weiler, 2012), but few focus on comparing tourists and local residents. Nevertheless, a few studies provide informative findings that ground our understanding of the differences between these two groups. Some studies find no statistical difference between residents and visitors in the mean scores of environmental concern (Leeworthy \& Wiley, 1996) and willingness to pay for a marine park 
fund (Ruitenbeek \& Cartier, 1999) or for beach water quality management (Penn, 2013), yet subtle differences between these groups with regard to specific issues might exist. A survey in Hawaii indicates that residents are more concerned about and feel more obligated to care for marine resources (Vaughan \& Ardoin, 2014). Díaz et al. (2010) study the valuation of landscape on a Spanish island and find that locals value natural components of the landscape higher than do tourists.

Other studies, including the present one, provide conflicting results. In Dowling's (1993) comparison of tourist and resident perceptions of tourism-environment relationships in Western Australia, tourists more strongly support greater environmental protection than do residents, echoing the value conflicts between residents and tourists with regard to a Canadian mountain park (Saremba \& Gill, 1991). Visitors to Provincetown Harbor, Massachusetts have more reservations about the expansion of shellfish aquaculture than do the generally supportive locals (Maggio, 2015). Garla et al. (2015) demonstrate that residents in the western South Atlantic hold fewer positive attitudes toward sharks than do tourists. More tourists than residents notice shark populations being affected by other species' fisheries, would approve the banning of shark fishing around Brazil's Fernando de Noronha archipelago, and are aware of some shark species being endangered. Likewise, Luksenburg and Parsons (2014) reveal that tourists are more concerned about threats to marine animals, particularly from overfishing, and have stronger preferences for seeing marine mammals in the wild rather than in a dolphinarium. In a Canadian case of Algonquin Provincial Park ecotourism, tourists exhibit stronger intentions of being environmentally responsible (Penney, 2014). The higher approval of conservation from visitors than from residents is seemingly more salient in the case of national parks. Szell (2012) finds that in terms of both awareness and appreciation of the protected areas in Retezat National Park, Romania, tourists score higher than locals.

Lower support for conservation among residents is usually associated with their dissatisfaction with the processes of establishing protected areas or tourism planning. In cases where residents have insufficient participation in planning processes (e.g. Dimitrakopoulos et al., 2010) and are restricted from accessing protected areas for economic activities such as agriculture and harvesting of natural resources (Brandon et al., 2005), locals often hold negative views of protected areas and environmental protection more broadly. Furthermore, in light of the collective opinion with regards to the relative emphasis on a place's economy or environment, societal value systems play a pivotal role. Post-modernization theory or theory of value change (Inglehart, 1997) could shed some light here. As a society undergoes transition from modernization to post-modernization, citizens' prevailing values shift from materialist to post-materialist views. Economic progress drives this cultural shift. In a modernized society, people prioritize existence needs, including security of life and property, reflecting materialist values. With the improvement of economic wellbeing, basic material needs are satisfied and gradually replaced by pursuit of higher goals such as self-expression, quality of life, and environmental protection. Post-materialist values emerge, and society enters a stage of post-modernization. Since environmental concerns are characteristic of post-materialist values (Inglehart, 1997), the attitudinal differences in conservation or environmental protection between residents and visitors-two groups of people who often possess unequal living conditions — can be understood as related to their different sets of fundamental values.

\section{Method}

\section{Participants}

Two hundred and fifty-five participants aged 20 and above and consisting of two groups of Wang-An residents and visitors were recruited. Residents were randomly sampled by drawing from house numbers, and one adult from each house was approached. Visitor participants were those who we randomly encountered on Wang-An island. As a result, 114 residents (76 males and 38 females, aged between 20 and 74) and 141 visitors (60 males and 81 females, aged between 20 and 70) participated in the survey. 
Instrument

A four-part questionnaire was developed, based on the literature and a pilot test:

- Ecotourism perception subscale: 15 items developed with reference to the definition and principles of ecotourism proposed by the International Ecotourism Society (2015) and Weaver and Lawton's (2002) items of ecotourism depth.

- Environmental attitude subscale: 14 items developed with reference to the New Ecological Paradigm Scale (NEP) (Dunlap et al., 2000).

- Ecotourism behaviour subscale: 32 items adapted from Weaver and Lawton's (2002) ecotourism behaviour scale.

- Local environmental knowledge test: 14 questions about local culture and green sea turtle ecology, developed by consulting local senior residents and a researcher from the green sea turtle conservation centre on Wang-An. The test contains 13 multiple-choice questions, each scoring one point, and one open question with scores between 0 and 2 , depending on the correctness and detail level of the answers written by respondents. The total score of the test ranges from 0 to 15 .

All subscales use a five-point Likert scale (Likert, 1932), with score 1 representing the lowest level of perception and behaviour or the least-approving attitude and score 5 representing the highest or the most. The internal consistency reliability, Cronbach's $\alpha$, of each subscale of this questionnaire is estimated on the basis of the results of a pilot test; 0.716 for the ecotourism perception subscale, 0.633 for the environmental attitude subscale, and 0.905 for the ecotourism behaviour subscale, indicating an approximate reliability of these subscales.

\section{Statistical analysis}

For the purpose of this study, comparisons between residents and visitors in four variables of ecotourism perception, behaviour, environmental attitude, and LEK were processed by employing Student $t$-tests and chi-square tests. Differences between the two groups of respondents in the scores of the four respective variables as well as scores of individual constituent items of the variables were tested for statistical significance with independent sample $t$-tests. Gender differences in these four variables within the resident group and within the visitor group were tested in the same way. The resident-visitor difference in the proportional distribution of answers to an LEK question was tested with the chi-square test of homogeneity that indicates whether the proportional distribution of residents' answers significantly differed from that of visitors' answers.

As a summative and visual presentation of differences between residents and visitors in these four variables, a fuzzy cluster analysis (Ruspini, 1969; Höppner et al., 1999), which is used to sort samples into groups, was conducted. Examples of its applications in clustering people include studies by Hogo (2010), Pond and Chini (2017), and Tsang et al. (2017). Unlike hard partition of data in which each observation is assigned exclusively to one cluster, fuzzy partition allows an observation to be assigned to more than one cluster (Döring et al., 2006), suggesting possible overlaps between the resultant clusters. The feature coincides with the situation of this study in which the resident group and visitor group could partially overlap across the spectrums of ecotourism perception, behaviour, and environmental attitude. Cluster analysis applies to observations without predefined class labels, which are processed by unsupervised classification (Tan et al., 2006). Although the classes of respondents in this study were known in advance as residents or visitors, this statistical technique is employed in order to see how residents and visitors were separated from each other in two generated clusters. The procedure consisted of reducing the four variables into two principal components through principal component analysis. Scores of the four variables of each respondent were thereby converted to two principal component scores from which a two-dimension scatter plot of all respondents was drawn. With the number of clusters set to be 
two and fuzzy clustering algorithm, points in the plot of two principal components were clustered. These were processed with the statistical program S-PLUS.

\section{Results}

\section{Ecotourism perception}

Residents had statistically lower scores on most items of ecotourism perception than did visitors. As a result, on average, residents scored 4.333 , lower than the 4.560 of visitors, though both were high on a five-point scale. Residents did not perceive ecotourism as having much emphasis on features such as appreciation, experiences, fewer environmental impacts, and environmental education.

\section{Environmental attitude}

Residents' scores were lower than visitors' on all environmental attitude items, with a statistically significant difference between residents' and visitors' scores on most items. Residents showed less approval for ideas about living harmoniously with nature, fragility of the natural environment, and limitation of natural resources but were more favourable about the instrumental value of plants and animals, human capacity to modify the environment, justification for altering the environment for social and economic development, and technology's ability to solve environmental pollution. Residents had a significantly lower mean score of all items (4.368) than did visitors (4.521).

\section{Ecotourism behaviour}

In terms of mean score of all ecotourism behaviour items, residents did not differ significantly from visitors. However, on the item level, 10 out of a total of 32 items had significant differences between the two groups of respondents, with visitors scoring higher than residents on seven of these items. That is, visitors had better performance on more than twice as many ecotourism behaviours than did residents.

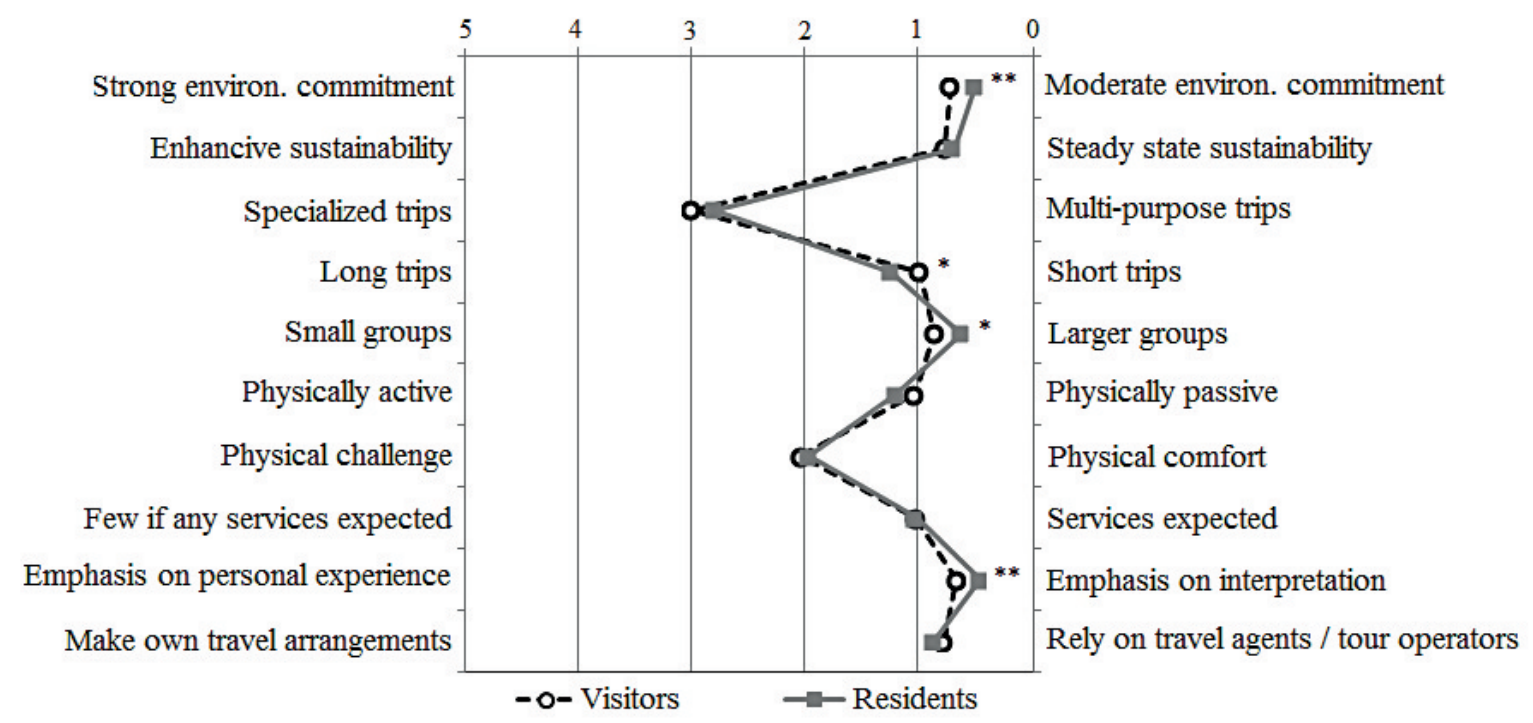

Figure 3: Score profiles of residents and visitors on deep-shallow ecotourism characteristics.

The seven behaviours refer to 'learning about the local natural environment', 'participation that makes me more environmentally conscientious', 'experiencing as many destinations as possible', 'the extent of prioritization of comfortable accommodations and services', 'willingness to donate money to support ecotourism sites', and 'impressing friends/family with the visited destinations'. 


\section{Ecotourism depth}

To see how residents and visitors were positioned between two ends of hard (active, deep) and soft (passive, shallow) ecotourism on ten characteristics (Weaver \& Lawton, 2002), we drew items with corresponding meanings from the ecotourism perception and behaviour subscales and plotted their scores. As Figure 3 depicts, score profiles of the two groups followed the same pattern, and the two curves overlapped. Symbols marked with asterisks indicate statistically significant differences between the two groups. Among the four characteristics with significant differences, visitors' scores were higher than residents' scores on the three characteristics of stronger environmental commitment, smaller groups, and emphasis on personal experience, indicating deeper perception and better performance in these characteristics.

\section{Local environmental knowledge}

Of the maximum total score of 15 , residents had an average total score of 9.263 , significantly exceeding that of 8.333 for visitors. Results of the chi-square test of homogeneity revealed that residents and visitors differed significantly from each other in the proportional distributions of answers for four questions. Except for a question concerning fruit being pickled for making sour melon, the two groups had roughly comparable proportions of correct answers for the remaining three questions. There were consistently higher proportions of visitors than residents choosing the answer 'I don't know' for all four questions on local environmental knowledge, resulting in the lower average total score of visitors.

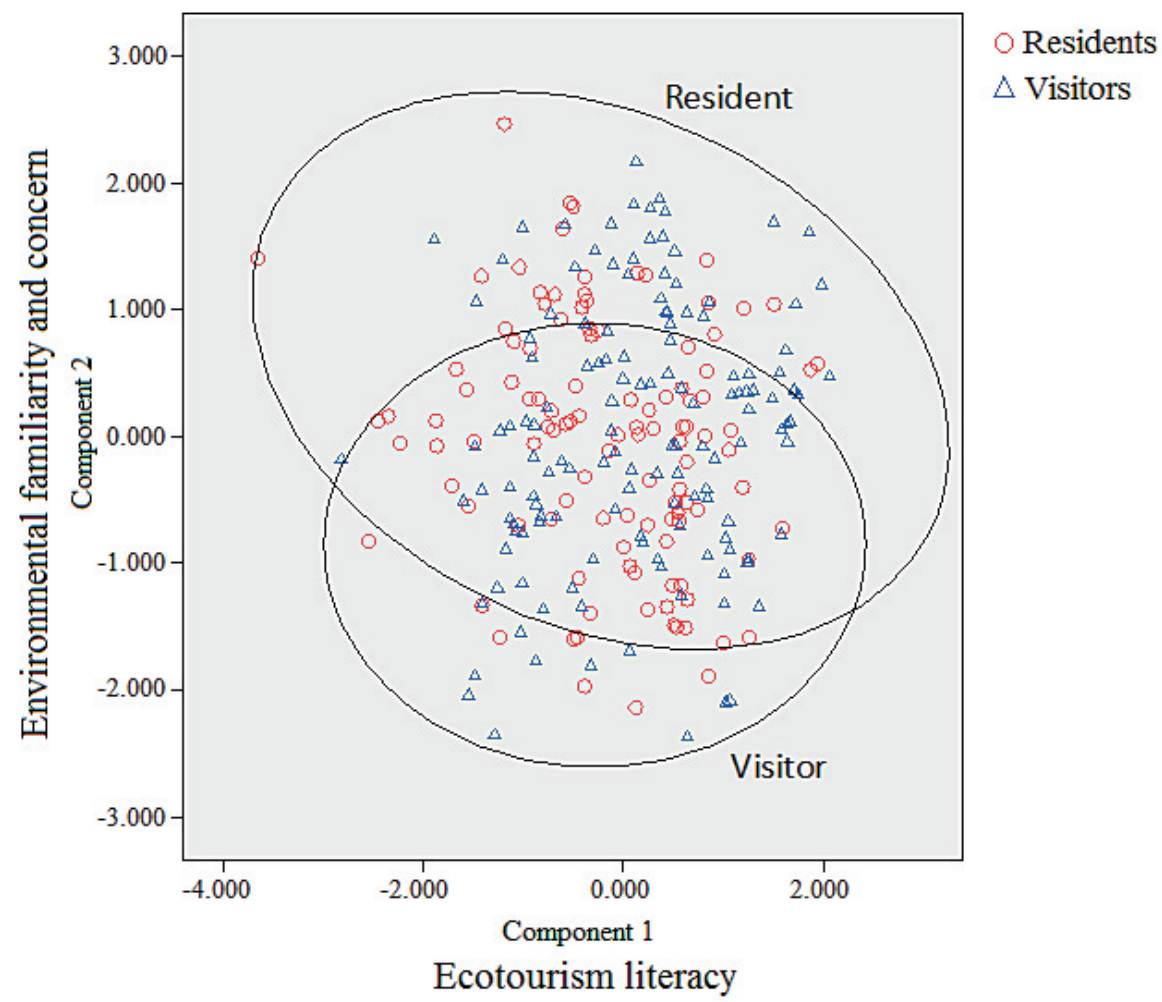

Figure 4: Cluster diagram of fuzzy cluster analysis.

Fuzzy cluster analysis

With principal component analysis that extracts a number of factors from a data set of variables, the four dimensions in which residents and visitors were compared (ecotourism perception, environmental attitude, ecotourism behaviour, and LEK) were reduced to two, as two axes of a cluster graph (Figure 4). Table 1 describes the contributions of the four variables to the two extracted principle components or factors. These two components explained $69.13 \%$ of the variance of the four variables, marginally satisfying the common rule of thumb of at least $70 \%$. 
Two variables (ecotourism perception and ecotourism behaviour) had greater loadings $(0.867$ and 0.791 ) on the first component, which was therefore termed 'ecotourism literacy'. The other two variables (environmental attitude and LEK) contributed more to the second component (with loadings of 0.598 and 635) than to the first component. Accordingly, the second component was termed 'environmental familiarity and concern'. Scores of four variables of each respondent were converted into the first and the second principal component scores, which were plotted and inputted for fuzzy cluster analysis. In the resultant graph of Figure 4, circles and triangles represent individual samples of residents and visitors respectively, and ellipses denote the clusters encircling samples that were assigned to them by fuzzy cluster analysis.

Table 1: Component matrix of principle component analysis with the four variables compared.

\begin{tabular}{|l|l|l|}
\hline & Component 1 & Component 2 \\
\hline Ecotourism perception & .867 & -.224 \\
\hline Environmental attitude & .484 & .598 \\
\hline Ecotourism behaviour & .791 & -.434 \\
\hline Local environmental knowledge & .391 & .635 \\
\hline
\end{tabular}

Note: Extraction method: Principal component analysis. Two components extracted.

There was large degree of overlap between the two clusters, which is normal in fuzzy clustering. With reference to the result of better resident LEK as well as the kinds of symbols around the rims of the ellipses, the larger ellipse at the top is identified as the cluster of residents while the other, smaller ellipse is the cluster of visitors. The smaller area of the visitor cluster indicated that, compared with residents, visitors had more consistent perceptions of ecotourism and similar levels of environmental familiarity and concern.

\section{Discussion}

On the shallow-deep spectrum of most of Weaver and Lawton's (2002) ecotourism characteristics, visitors to Wang-An placed themselves close to the deep end, which emphasizes minimum impacts on destination environments. This is consistent with the results of the environmental attitude sub-scale and could be attributed to the more positive environmental attitude of visitors than of residents. Since tourism per se is an economic activity, with respect to the perception of ecotourism, visitors' stronger environmental concern is often contrasted with the findings of residents' greater emphasis on the economy. For example, for the statement that 'Sometimes humans are compelled to alter nature for the sake of social and economic development, and it can be regarded as positive', residents expressed significantly more approval than did visitors. Penney (2014) also found that tourists were more concerned with the environmental impacts of ecotourism while residents' perspectives often added more economic considerations.

The more reserved environmental attitude of residents, compared with that of visitors, might have some relevance to the discontent that some locals express with past processes of establishing protected areas. The study of Penghu tourism by Hsu et al. (2011) indicates that some residents are unsatisfied with the green sea turtle protection area. Yet the relative weighting between environmental protection and economic development in one's mind could better account for the different views residents and visitors hold toward the local environment. Our result, reflecting a latent preference for economic development among residents, parallels Penney's (2014) argument that, for residents, the local environment represents livelihood, but visitors see it as 'pristine nature'. 
In Taiwan, it has long been acknowledged that residents of outlying islands and remote, rural areas hold values that accentuate local economic growth, idealistically expecting a level of prosperity comparable to those of major cities. Because visitors are mostly from places with better living conditions, according to Inglehart's (1997) post-modernization theory, they possess a relatively satisfactory status of economic wellbeing and hold post-materialistic values. Just as a cross-national study (Oreg \& Katz-Gerro, 2006) has found these values to be positively related to environmental concerns, visitors exhibit more positive environmental attitudes than do residents. A local study that focuses on urban-rural value differences is supportive of this argument: Wu (2015) investigates Taiwan's citizens and finds that, in metropolitan areas with better economic conditions, there is a larger proportion of people possessing post-materialistic values and approving of environmental protection, whereas in non-urban areas, most people have materialistic values, which emphasize economic development. Despite the weakness recognized in Inglehart's (1997) post-modernization theory, "it provides useful insights as to how and why ideology is changing in response to material forces in the twenty-first century" (Manfredo, 2008, p. 183) and is empirically supported regarding environmental concern (e.g. Oreg \& Katz-Gerro, 2006; Franzen \& Meyer, 2010). Postmodernization theory thus lends explanatory power to the results observed in this study.

Although no statistically significant gender difference was found in the overall environmental attitudes of either residents or visitors, male residents significantly scored lower than did female residents on a few items regarding the instrumental value of plants and animals for human utilization, the capability of humans to modify the environment, justification for altering the environment for social and economic development, and the ability of technology to solve environmental pollution. This is consistent with previous studies finding that females are more concerned about the environment than are males (Cottrell, 2003; Dietz, Kalof, \& Stern, 2002; Hunter et al., 2004). Brough et al. (2016) summarize a number of reasons for this. Bearing in mind the absence of this subtle gender difference among visitors, we hypothesize that male residents of this relatively non-urbanized small island and relatively traditional society tend to assume more responsibility in family livelihood than do females and therefore show less approval toward some pro-environmental notions. Indeed, in Wu's (2015) study, compared with the urbanized capital city of Taipei, males in less-urbanized parts of Taiwan are less likely to approve of environmental protection than are females.

Wang-An residents are unsurprisingly more knowledgeable about local traditional culture, yet they know less about green sea turtles than do visitors, consistent with Chang's (2011) finding that no sampled Wang-An residents mention green sea turtles when asked about perceptions of the island. Szell and Hallett (2013) also find less knowledge about the local environment in residents than in visitors. There are two potential explanations for this information asymmetry in local ecological knowledge concerning sea turtles. Firstly, it could be a result of loss of traditional ecological knowledge attributable to a number of causes, including urbanization and associated socioeconomic changes (Cetinkaya, 2009; Cristancho \& Vining, 2004; McDaniel \& Alley, 2005; Nagy \& Lockaby, 2011; Ross, 2002; Silvano \& Begossi, 2010; Turner \& Turner, 2008), restricted access to protected areas (Gomez-Baggethun et al., 2010; Turner \& Turner, 2008), schooling (Reyes-García et al., 2010; Tsuji \& Nieboer, 1999), and malfunctioning mechanisms of knowledge transmission (Takako, 2004). In Penghu, the chain of knowledge inheritance from ancestors could have been disrupted. Recent decades of urbanization may have reduced islanders' exposure to the natural environment, which Guest (2002) regards as key to an individual's LEK. As an island urbanizes and its economy shifts from fishing to tourism, residents have less contact with sea turtles, leaving less knowledge to descendants. Traditional ecological knowledge, a crucial component of LEK, is insight obtained through extensive observation of a species (Huntington, 2000). Residents' observation of sea turtles must thus be examined in terms of opportunities, frequency of contacts, and impressions.

Secondly, since visitors possess knowledge about green sea turtles, it is less a loss of LEK than the transfer, assimilation, or evolution of LEK. "Traditional knowledge outputs have taken on their own social lives," sometimes being used for new purposes (Bonny \& Berkes, 2008, p. 250), and when LEK is institutionalized, it can be archived and transferred (Briggs, 2005). Alexiades (2009) regards 
the representation of LEK as a central issue. We postulate that local knowledge about green sea turtles has been represented in science and education. Marine biologists collected, documented, and represented this knowledge in scientific reports and books, on which the contents of educational materials and exhibitions in conservation centres are now based. It is noteworthy that this process is not merely a flow of LEK from residents to scientists but also an integration of both local and scientific forms of knowledge. Involved in this process are translation, verification, and transformation of local knowledge into scientific knowledge (Johnson, 2009). Unfortunately, this knowledge flow seems to be unidirectional. In a case of sea turtles in Mexico, scientists rarely returned once they collected the data (Küyük et al., 2007). In the present study, residents are presumably left to consider information sources such as the green sea turtle conservation centre and educational materials designed for tourists - precisely the kinds of information that residents habitually ignore. The green sea turtle conservation centre turns out to be the 'terminal station' to which local knowledge about the species is transferred and where it is displayed primarily for tourists.

Local political ecology is also relevant to the disparity in residents' and visitors' local ecological knowledge. Accounts of nature are conditioned and stabilized by social structures of power (Robbins, 2012). The influence of power in indigenous or traditional ecological knowledge has been studied in terms of interactions between locals and 'outsiders' such as scientists, nation-states (Robins, 2000), and other locals who control resources for livelihoods (Crona \& Bodin, 2010), yet such power relationships have received little study with reference to locals and visitors. Further study is needed to identify sources of power and the processes by which power affects the unequal knowledge gain between island residents and visitors. Alternatively, residents' relative ignorance concerning green sea turtles could be a matter of the forms of knowledge with which visitors and residents are familiar. Residents might not be as good as visitors at the surface commonsense of local ecology but may possess tacit knowledge that is implicit and difficult for visitors to learn.

Generally speaking, differences in resident and visitor ecotourism behaviour reflect different inclinations in their environmental attitudes. As Penney (2014, pp. 101-102) explains, treating the place as 'Nature', visitors express a strong intent to be environmentally responsible and therefore realize principles of ecotourism such as "engagement with and enjoyment of nature, and environmental awareness and responsibility." The present study did not uncover similarities with Vaughan and Ardoin's (2014) findings that visitors tend to focus on personal behaviours such as picking up one's own trash while residents tend to influence others' behaviour with education and enforcement.

As Figure 4 demonstrates, the noticeable separation between the two clusters occurs in the dimension of the second component, termed 'environmental familiarity and concern'. This separation is essentially a result of the higher LEK of residents than of visitors, as the result of the test of mean differences suggests-particularly with regard to knowledge about local traditions. However, the wider span of the resident cluster demonstrates the greater dispersion of samples in the dimension of ecotourism literacy. Residents' ecotourism perception and behaviour are relatively divergent on a quantified scale. The distribution of resident (circles) and visitor (triangles) samples in Figure 4 indicates the scatter of some residents adjacent to the deficient or negative end of the ecotourism literacy dimension, falling behind the range across which visitors are densely distributed.

Ideally, both clusters of residents and visitors should shift to the quadrant with higher environmental familiarity and concern as well as more ecotourism literacy, i.e. Quadrant I in Figure 4, with the area of the resident cluster being reduced. The resident cluster should still be placed slightly higher than the visitor cluster as residents typically know the local environment better than do visitors. Longer tourist stays and environmental education could be influential in shifting two clusters from the present central, cross-quadrant position toward the ideal Quadrant I. Interactions between residents and visitors would increase over a longer stay and enable more mutual learning. Visitors would learn more about local culture and ecology from residents and would have more experiences with the local environment. As to fostering more positive environmental attitudes, residence and direct interaction with the environment also play an important role in connecting visitors with place and forming a sense of responsibility toward place 
(Lewicka, 2005; Morgan, 2009). This approach of longer stays could facilitate the upward movement of the visitor cluster in the dimension of environmental familiarity and concern.

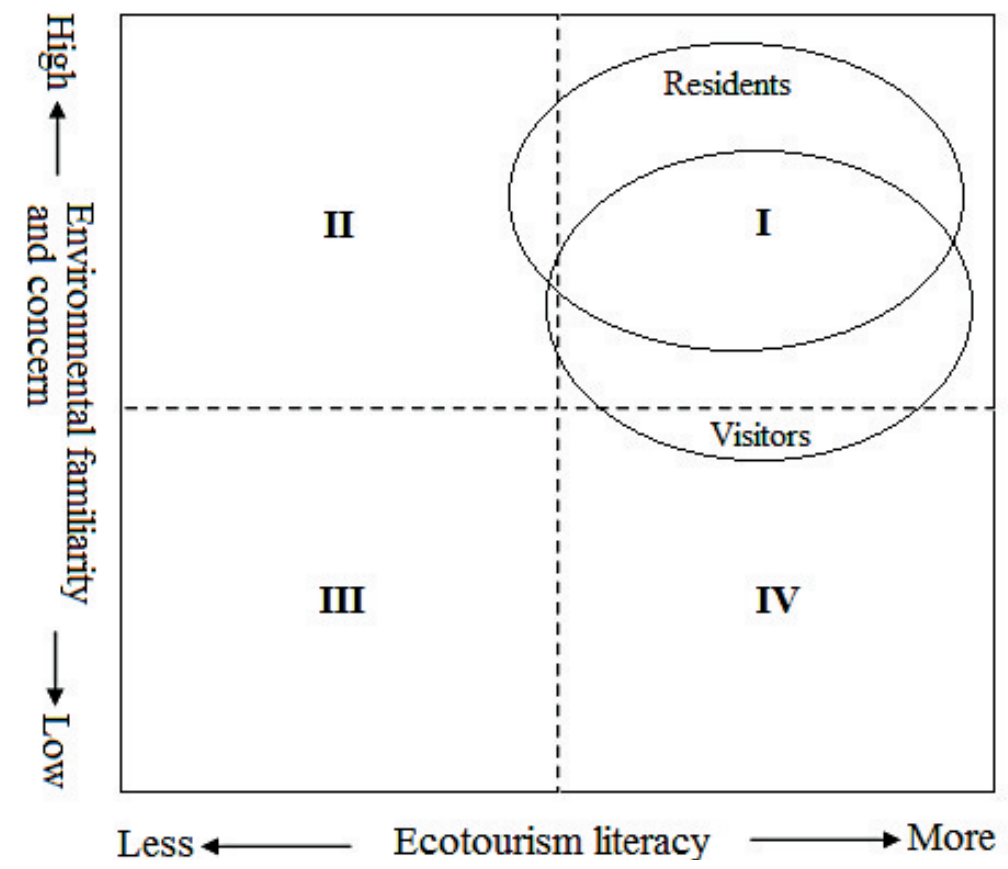

Figure 5: Ideal position of resident and visitor clusters.

Similarly, interactions with visitors who enthusiastically pursue deeper ecotourism could foster greater ecotourism literacy among residents. Environmental education is also necessary for changing residents' perception and behaviour of ecotourism and for moving the resident cluster rightward in the dimension of ecotourism literacy. It is crucial to devise environmental education programmes tailored to ecotourism in Penghu in general and Wang-An in particular. This study's findings suggest benefits to devising educational activities specifically dealing with residents' misunderstandings regarding local economics and livelihoods: efforts should be made to clarify how ecotourism perception and behaviour are linked to livelihoods and ultimately to prospects for community sustainability on Wang-An. Unlike most studies that stress the advantages of ecotourism as a form of environmental education (e.g. Kimmel, 1999; Orams, 1997; Tisdell \& Wilson, 2005), in which visitors are the subjects of concern, future studies should be more attentive to environmental education aimed at residents and showing how ecotourism is integral to island livelihoods. Utilizing LEK to create economic benefits as well as advance the perception of tourism could be advantageous for residents, who could benefit from the production, preservation, and circulation of local ecological knowledge in terms of employment, resources, income, and prestige (Reid et al., 2002). Economic benefits could inspire local community participation in ecotourism (Masud et al., 2017).

There is likewise a need for future investigation into those who possess LEK-whether elders or men and women with expertise in various types of local knowledge. As Fitzgerald and Stronza (2016) contend, tourism has been a cornerstone of protected areas worldwide. Grasping residents' interest in the developmental or tourism facet of ecotourism while expediently approaching ecotourism as a delicate and upgraded edition of tourism might be a preliminary and advantageous means of guiding residents toward a deeper form of ecotourism.

\section{Conclusion}

Through a statistical test of differences in means and a two-dimension cluster graph, this study numerically and visually presents the differences between visitors to and residents of the small 
island of Wang-An in terms of ecotourism perception, ecotourism behaviour, environmental attitude, and local environmental knowledge (LEK). Residents were found to perform especially well at knowledge concerning traditional customs (a part of LEK) but were less literate in ecotourism than were visitors in terms of perception and behaviour. A significant number of residents valued economic prosperity over environmental conservation, resulting in residents as a whole tending toward the shallow side of a diagram depicting deep-shallow ecotourism characteristics. Visitors showed greater preference for a number of characteristics of deep ecotourism, such as stronger environmental commitment, smaller groups, and emphasis on personal experience. The finding that residents did not necessarily know green sea turtles better than did visitors suggests a need for future studies exploring more subtle and tacit knowledge that residents learn from their living in the local environment.

Results of fuzzy cluster analysis showed a discernible separation between two clusters of residents and visitors in the dimension of environmental familiarity and concern, though these two groups largely overlap. It is expected that, in the future, the two clusters will move together toward an ideal quadrant with greater ecotourism literacy and higher environmental familiarity and concern. Where interactions between residents and visitors exist, it might be feasible for visitors with deeper ecotourism perception to recognize themselves as not just consumers of local tourism but also educators of ecotourism to residents. Consequently, consumer and educational forces should collectively drive the practice of Wang-An ecotourism and residents' ecotourism literacy toward the deeper end of the ecotourism spectrum. Meanwhile, residents with inherently better LEK would be competent in leading in-depth learning on the part of visitors with regard to the island's culture and ecology. This mutual learning strategy is presumably best realized over longer tourist stays, and the promotion of ecotours with more days of residence on Wang-An or in Penghu is recommended.

A few limitations to our study must be considered. Some data that would lend more support to our explanation of results is lacking, including the frequency of residents' visits to the green sea turtle conservation centre and the experience of researchers who could advise on the integration of local ecological knowledge into educational materials for the public. In addition, the number of LEK questions may be insufficient, limiting verification of the effects of LEK. The findings of the present study nevertheless add to the body of knowledge concerning two major populations of ecotourism, considering an aspect that had hitherto not been fully investigated. The study results also imply a need for strategic policy improvement in transforming conventional tourism to sustainable tourism on small islands such as Wang-An and in archipelagos such as Penghu. For instance, a certification programme for the 'greenness' of tour packages for both consumers and operators of ecotourism could be an action of practical significance. Policy planners as well as environmental educators should be able to derive useful ideas from this study's results concerning ecotourism perception profiles and cluster distribution of residents and visitors.

\section{References}

Alexiades, M.N. (2009). The cultural and economic globalisation of traditional environmental knowledge systems. In S. Heckler (Ed.), Landscape, process and power: re-evaluating traditional environmental knowledge (pp. 68-90). New York: Berghahn.

Bell, S., Hampshire, K., \& Tonder, M. (2008). Person, place, and knowledge in the conservation of the Saimaa ringed seal. Society and Natural Resources, 21(4), 277-293. https://doi.org/10.1080/08941920701860516

Bonny, E., \& Berkes, F. (2008). Communicating traditional environmental knowledge: addressing the diversity of knowledge, audiences and media types. Polar Record, 44(230), 243-253. https://doi.org/10.1017/S0032247408007420

Brandon, K., Gorenflo, L., Rodrigues, A., \& Waller, R. (2005). Reconciling biodiversity conservation, people, protected areas, and agricultural suitability in Mexico RID A-5914-2009. World Development, 33(9), 1403-1418. https://doi.org/10.1016/j.worlddev.2004.10.005 
Briggs, J. (2005). The use of indigenous knowledge in development: problems and challenges. Progress in Development Studies, 5(2), 99-114. https://doi.org/10.1191/1464993405ps105oa Brough, A.R., Wilkie, J.E.B., Ma, J., Isaac, M.S., \& Gal, D. (2016). Is eco-friendly unmanly? The green-feminine stereotype and its effect on sustainable consumption. Journal of Consumer Research, 43(4), 567-582. https://doi.org/10.1093/jcr/ucw044

Cetinkaya, G. (2009). Challenges for the maintenance of traditional knowledge in the Satoyama and Satoumi ecosystems, Noto Peninsula, Japan. Research in Human Ecology, 16(1), 27-40.

Chang, Y.H. (2011). Local residents attitude toward the 'Green Sea Turtle Ecotourism' upon their island home - a case study of Wang-Ann Island, Penghu Archipelago (Unpublished master thesis). National Taiwan Normal University. (in Chinese)

Cottrell, S.P. (2003). Influence of sociodemographics and environmental attitudes on general responsible environmental behavior among recreational boaters. Environment and Behavior, 35(3), 347-375. https://doi.org/10.1177/0013916503035003003

Cristancho, S., \& Vining, J. (2004). Reciprocity as principled argument: the ethics of humannature interactions for the Letuama. Human Ecology Review, 11(1), 36-49.

Crona, B., \& Bodin, Ö. (2010). Power asymmetries in small-scale fisheries: a barrier to governance transformability? Ecology and Society, 15(4), 32. https://doi.org/10.5751/ES-03710-150432

Díaz, P., Ruiz-Labourdette, D., Rodríguez Darias, A., Santana, A., Schmitz, M.F., \& Pineda, F.D. (2010). Landscape perception of local population: relationship between ecological characteristics, local society and visitor preferences. In C.A. Brebbia \& F.D. Pineda (Eds.), Sustainable tourism IV (pp. 309-318). London: WIT Press. https://doi.org/10.2495/ST100271

Dietz, T., Kalof, L., \& Stern, P.C. (2002). Gender, values, and environmentalism. Social Science Quarterly, 83(1), 353-364. https://doi.org/10.1111/1540-6237.00088

Dimitrakopoulos, P.G., Jones, N., Iosifides, T., Florokapi, I., Lasda, O., Paliouras, F., \& Evangelinos, K.I. (2010). Local attitudes on protected areas: evidence from three natural 2000 wetland sites in Greece. Journal of Environmental Management, 91(9), 1847-1854. https://doi.org/10.1016/j.jenvman.2010.04.010

Döring, C., Lesot, M.-J., \& Kruse, R. (2006). Data analysis with fuzzy clustering methods. Computational Statistics \& Data Analysis, 51, 192-214. https://doi.org/10.1016/j.csda.2006.04.030

Dowling, R.K. (1993). Tourist and resident perceptions of the environment-tourism relationship in the region, Western Australia. GeoJournal, 29(3), 243-251. https://doi.org/10.1007/BF00807043

Dunlap, R.E., Van Liere, K.D., Mertig, A.G., \& Jones, R.E. (2000). New trends in measuring environmental attitudes: measuring endorsement of the new ecological paradigm: a revised NEP scale. Journal of Social Issues, 56(3), 425-442. https://doi.org/10.1111/0022-4537.00176

Fitzgerald, L.A., \& Stronza, A.L. (2016). In defense of the ecotourism shield: a Response to Geffroy et al. Trends in Ecology and Evolution, 31(2), 94-95. https://doi.org/10.1016/j.tree.2015.11.002

Formica, S., \& Uysal, M. (2001). Segmentation of travellers based on environmental attitudes. Journal of Hospitality E Leisure Marketing, 9(3-4), 35-49. https://doi.org/10.1300/J150v09n03 04

Garla, R.C., Freitas, R.H.A., Calado, J.F., Paterno, G.B.C., \& Carvalho, A.R. (2015). Public awareness of the economic potential and threats to sharks of a tropical oceanic archipelago in the western South Atlantic. Marine Policy, 60, 128-133. https://doi.org/10.1016/j.marpol.2015.06.012

Gawler, M. (1998). What are best practices? Lessons in participatory management of inland and coastal wetlands. In M. Gawler (Ed.), Strategies for wise use of wetlands: best practices in participatory management: proceedings of a workshop held at the 2nd International Conference on Wetlands and Development (November 1998, Dakar, Senegal).

Gomez-Baggethun, E., Mingorria, S., Reyes-García, V., Calvet, L., \& Montes, C. (2010). Traditional ecological knowledge trends in the transition to a market economy: empirical study in the Donana natural areas. Conservation Biology, 24(3), 721-729. https://doi.org/10.1111/j.1523-1739.2009.01401.x

Guest, G. (2002). Market integration and the distribution of ecological knowledge within an Ecuadorian fishing community. Journal of Ecological Anthropology, 6(1), 38-49. https://doi.org/10.5038/2162-4593.6.1.3 
Hogo, M.A. (2010). Evaluation of e-learners behaviour using different fuzzy clustering models: a comparative study. International Journal of Computer Science and Information Security, 7(2), 131-140.

Höppner, F., Klawonn, F., \& Kruse, R. (1999). Fuzzy cluster analysis: methods for classification, data analysis, and image recognition. New York: John Wiley \& Sons.

Hsu, C.H., Chuang, C. T., \& Chen, S.C. (2011). Marine and island ecotourism in the Pescadores Archipelago, Taiwan. International Journal of Agricultural Travel and Tourism, 2(1), 48-60.

Hunter, L.M., Hatch, A., \& Johnson, A. (2004). Cross-national gender variation in environmental behaviors. Social Science Quarterly, 85(3), 677-694. https://doi.org/10.1111/j.0038-4941.2004.00239.x

Huntington, H.P. (2000). Using traditional ecological knowledge in science. Ecological Applications, 10(5), 1270-1274. https://doi.org/10.1890/1051-0761(2000)010[1270:UTEKIS]2.0.CO;2

Inglehart, R. (1997). Modernization and postmaterialism: cultural, economic, and political change in 43 societies. Princeton, NJ: Princeton University Press.

Johannes, R., \& Neis, B. (2007). The value of anecdote. In N. Haggan, B. Neis, \& I. Baird (Eds.), Fishers' knowledge in fisheries science and management (pp. 21-36). Paris: UNESCO.

Johnson, T.R. (2009). Cooperative research and knowledge flow in the marine commons. International Journal of the Commons, 4(1), 251-272. https://doi.org/10.18352/ijc.110

Jurowski, C., Uysal, M., Williams, D. R., \& Nog, F. P. (1995). An examination of preferences and evaluations of visitors based on environmental attitudes: Biscayne Bay National Park. Journal of Sustainable Tourism, 3(2), 73-86. https://doi.org/10.1080/09669589509510712

Kim, A.K.J., \& Weiler, B. (2012). Visitors' attitudes towards responsible fossil collecting behaviour: an environmental attitude-based segmentation approach. Tourism Management, 36, 602-612. https://doi.org/10.1016/j.tourman.2012.08.005

Kimmel, J.R. (1999). Ecotourism as environmental learning. The Journal of Environmental Education, 30(2), 40-44. https://doi.org/10.1080/00958969909601869

Kimmerer, R.W. (2002). Weaving traditional ecological knowledge into biological education: a call to action. Bioscience, 52(5), 432-438. https://doi.org/10.1641/00063568(2002)052[0432:WTEKIB]2.0.CO;2

Küyük, K.E., Nichols, W.J., \& Tambiah, C.R. (2007). The value of local knowledge in sea turtle conservation: a case from Baja California, Mexico. In N. Haggan, B. Neis, \& I. Baird (Eds.), Fishers' knowledge in fisheries science and management (pp.262-275). Paris: UNESCO.

Leeworthy, V.R., \& Wiley, P.C. (1997). A socioeconomic analysis of the recreation activities of Monroe County residents in the Florida Keys/Key West: linking the economy and environment of Florida Keys/Florida Bay. Silver Spring, MD: National Oceanic and Atmospheric Administration, Strategic Environmental Assessments Division.

Lewicka, M. (2011). Place attachment: how far have we come in the last 40 years? Journal of Environmental Psychology, 31(3), 207-230. https://doi.org/10.1016/j.jenvp.2010.10.001

Likert, R. (1932). A technique for the measurement of attitudes. Archives of Psychology, 140, 1-55.

Luksenburg, J.A., \& Parsons, E.C.M. (2014). Attitudes towards marine mammal conservation issues before the introduction of whale-watching: a case study in Aruba (southern Caribbean). Aquatic Conservation: Marine and Freshwater Ecosystems, 24(1), 135-146. https://doi.org/10.1002/aqc.2348

Lye, T.P. (2007). Landscape knowledge in Cambodia: notes towards a methodology. Papers presented in the Seventh Annual Conference of Asian Scholar Foundation, Bangkok, 8-9, July.

Maggio, D. (2015). The recreational use of Provincetown harbor and attitudes towards shellfish aquaculture (Unpublished thesis). University of Rhode Island.

Manfredo, M.J. (2008). Who cares about wildlife? Social science concepts for exploring human-wildlife relationships and conservation issues. New York: Springer.

Masud, M.M., Aldakhil, A.M., Nassani, A.A., \& Azam, M.N. (2017). Community-based ecotourism management for sustainable development of marine protected areas in Malaysia. Ocean and Coastal Management, 136, 104-112. https://doi.org/10.1016/j.ocecoaman.2016.11.023 
McDaniel, J., Alley, K.D. (2005). Connecting local environmental knowledge and land use practices: a human ecosystem approach to urbanization in West Georgia. Urban Ecosystems, 8, 23-38. https://doi.org/10.1007/s11252-005-1417-2

Mehmetoglu, M . (2010). Accurately identifying and comparing sustainable tourists, nature-based tourists, and ecotourists on the basis of their environmental concerns. International Journal of Hospitality \& Tourism, 11(2), 171-199. https://doi.org/10.1080/15256481003732840

Miller, M.L., \& Kaae, B.C. (1993). Coastal and marine ecotourism: a formula for sustainable development? Trends, 30(1), 35-41.

Morgan, M. (2009). Interpretation and place attachment: implications for cognitive map theory. Journal of Interpretation Research, 14(1), 47-59.

Nagy, R.C., \& Lockaby, B.G. (2011). Urbanization in the southeastern United States: socioeconomic forces and ecological responses along an urban-rural gradient. Urban Ecosystems, 14(1), 71-86. https://doi.org/10.1007/s11252-010-0143-6

Orams, M.B. (1997). The effectiveness of environmental education: can we turn tourists into 'greenies'? Progress in Tourism and Hospitality Research, 3(4), 295-306. https://doi.org/10.1002/(SICI)1099-1603(199712)3:4<295::AID-PTH85>3.0.CO;2-D

Oreg, S., \& Katz-Gerro, T. (2006). Predicting proenvironmental behavior cross-nationally. Environment and Behavior, 38(4), 462-483. https://doi.org/10.1177/0013916505286012

Penn, J.M. (2013). Valuation of recreational beach quality and water quality management strategies in Oahu (Unpublished thesis). University of Kentucky.

Penney, E. (2014). In the eye of the beholder: perceptions of ecotourism in Algonquin Provincial Park (Unpublished thesis). University of Waterloo.

Pond, J.W.T., \& Chini, J.J. (2017). Exploring student learning profiles in algebra-based studio physics: a person-centered approach. Physical Review Physics Education Research, 13(1). https://doi.org/10.1103/PhysRevPhysEducRes.13.010119

Puhakka, R. (2011). Environmental concern and responsibility among nature tourists in Oulanka PAN Park, Finland. Scandinavian Journal of Hospitality and Tourism, 11(1), 76-96. https://doi.org/10.1080/15022250.2011.532589

Reid, A., Teamey, K., \& Dillon, J. (2002). Traditional ecological knowledge for learning with sustainability in mind. The Trumpeter, 18(1), 113-136.

Reyes-García, V., Kightley, E., Ruiz-Mallén, I., Fuentes-Peláez, N., Demps, K., Huanca, T., \& Martínez-Rodríguez, M.R. (2010). Schooling and local environmental knowledge: do they complement or substitute each other? International Journal of Educational Development, 30, 305-313. https://doi.org/10.1016/j.ijedudev.2009.11.007

Robbins, P. (2000). The practical politics of knowing: state environmental knowledge and local political economy. Economic Geography, 76(2), 126-144. https://doi.org/10.2307/144550

Robbins, P. (2012). Political ecology: a critical introduction (2nd ed.). London: Wiley-Blackwell.

Robertson H.A., \& McGee T.H. (2003). Applying local knowledge: the contribution of oral history to wetland rehabilitation at Kanyapella Basin, Australia. Journal of Environmental Management, 69(3), 275-287. https://doi.org/10.1016/S0301-4797(03)00155-5

Ross, N. (2002). Cognitive aspects of intergenerational change: mental models, cultural change and environmental behavior among the Lacandon Maya of Southern Mexico. Human Organization, 61(2), 125-137. https://doi.org/10.17730/humo.61.2.9bhqghxvpfh2qebc

Ruitenbeek, H.J., \& Cartier, C.M. (1999). Prospecting for marine biodiversity: a case study in Montego Bay, Jamaica. In K. Turner, I. Bateman, \& N. Adger (Eds.), Economics of coastal and water resources: valuing environmental functions (pp. 281-304). Dordrecht: Kluwer.

Ruspini, E. H. (1969). A new approach to clustering. Information and Control, 15(1), 22-32. https://doi.org/10.1016/S0019-9958(69)90591-9

Saremba, J., \& Gill, A. (1991). Value conflicts in mountain park settings. Annals of Tourism Research, 18(3), 455-472. https://doi.org/10.1016/0160-7383(91)90052-D 
Scholz, A., Bonzonb, K., Fujitab, R., Benjaminc, N., Woodlingd, N., Blackb, P., \& Steinback, C. (2004). Participatory socioeconomic analysis: drawing on fishermen's knowledge for marine protected area planning in California. Marine Policy, 28(4), 335-349. https://doi.org/10.1016/j.marpol.2003.09.003

Silvano, R.A.M., \& Begossi, A. (2010). What can be learned from fishers? An integrated survey of fishers' local ecological knowledge and bluefish (Pomatomus saltatrix) biology on the Brazilian coast. Hydrobiologia, 637(1), 3-18. https://doi.org/10.1007/s10750-009-9979-2

Silverberg, K.E. Backman, S. J., \& Backman, K.F. (1996). A preliminary investigation into the psychographics of nature-based travelers to the Southeastern United States. Journal of Travel Research, 35(2), 19-28. https://doi.org/10.1177/004728759603500204

Szell, A.B. (2012). Attitudes and perceptions of local residents and tourists toward the protected area of Retezat National Park, Romania (Unpublished thesis). Western Michigan University.

Szell, A.B, \& Hallett, L.F. (2013). Attitudes and perceptions of local residents and tourists toward the protected area of Retezat National Park, Romania. International Journal of Humanities and Social Science, 3(4), 18-34.

Takako, H. (2004). Nature of traditional ecological knowledge loss: a quantitative approach. Policy Science, 11(2), 147-156.

Tan, P.N., Steinbach, M., \& Kumar, V. (2006). Cluster analysis: basic concepts and algorithms. In Introduction to data mining (pp. 487-567). Boston: Addison-Wesley.

The International Ecotourism Society (2015). What is ecotourism? Retrieved from: http://www.ecotourism.org/what-is-ecotourism

Tisdell, C., \& Wilson, C. (2005). Perceived impacts of ecotourism on environmental learning and conservation: turtle watching as a case study. Environment, Development and Sustainability, 7(3), 291-302. https://doi.org/10.1007/s10668-004-7619-6

Tsang, S.S., Wang, W.C., \& Ku, H.H. (2017). Study on cluster analysis characteristics and classification capabilities: a case study of satisfaction regarding hotels and bed \& breakfasts of Chinese tourists in Taiwan. Intelligent Automation \& Soft Computing, 23(1), 103-108. https://doi.org/10.1080/10798587.2016.1139285

Tsuji, L.J.S., \& Nieboer, E. (1999). A question of sustainability in Cree harvesting practices: the seasons, technological and cultural changes in the western James Bay region of northern Ontario, Canada. Canadian Journal of Native Studies, 19(1), 169-192.

Turner N.J, \& Turner, K. (2008). Where our women used to get the food: cumulative effects and loss of ethnobotanical knowledge and practice: case study from coastal British Columbia. Botany, 86, 103-115. https://doi.org/10.1139/B07-020

Uysal, M., Jurowski, C, Noe, F.P., \& McDonald, C.D. (1994). Environmental attitude by trip and visitor characteristics: US Virgin Islands National Park. Tourism Management, 15(4), 284-294. https://doi.org/10.1016/0261-5177(94)90046-9

Vaughan, M.B., \& Ardoin, N.M. (2014). The implications of differing tourist/resident perceptions for community-based resource management: a Hawaiian coastal resource area study. Journal of Sustainable Tourism, 22(1), 50-68. https://doi.org/10.1080/09669582.2013.802326

Walter, P. (2009). Local knowledge and adult learning environmental adult education: community-based ecotourism in southern Thailand. International Journal of Lifelong Education, 28(4), 513-532. https://doi.org/10.1080/02601370903031363

Weaver, D.B., \& Lawton, L.J. (2002). Overnight ecotourist market segmentation in the Gold Coast hinterland of Australia. Journal of Travel Research, 40(3), 270-280. https://doi.org/10.1177/004728750204000305

Wu, C.L. (2015). Economic development vs. environmental protection: regional differences of the post-materialism value in Taiwan. Nanhua Journal of Social Sciences, 1, 35-62. (in Chinese)

Zelezny, L.C., Chua, P.P., \& Aldrich, C. (2000). Elaborating on gender differences in environmentalism. Journal of Social Issues, 56(3), 443-457. https://doi.org/10.1111/0022-4537.00177

Zografos, C., \& Allcroft, D. (2007). The environmental values of potential ecotourists: a segmentation study. Journal of Sustainable Tourism, 15(1), 44-66. https://doi.org/10.2167/jost572.0 